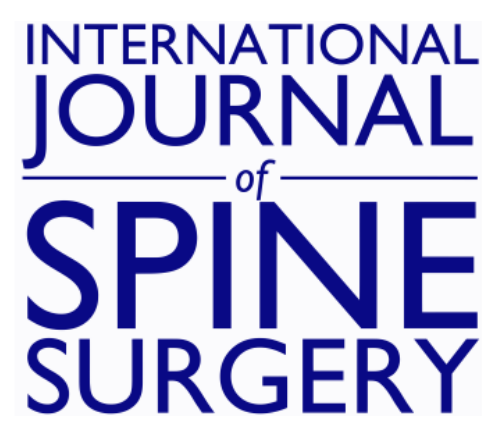

\title{
Cervical Disc Arthroplasty: Rationale and History
}

Peter B. Derman and Jack E. Zigler

Int J Spine Surg 2020, 14 (s2) S5-S13

doi: https://doi.org/10.14444/7086

http://ijssurgery.com/content/14/s2/S5

This information is current as of April 26, 2023.

Email Alerts Receive free email-alerts when new articles cite this article. Sign up at: http://ijssurgery.com/alerts 


\title{
Cervical Disc Arthroplasty: Rationale and History
}

\author{
PETER B. DERMAN, MD, MBA, JACK E. ZIGLER, MD \\ Texas Back Institute, Plano, Texas
}

\begin{abstract}
Biomechanical studies have demonstrated that cervical fusion results in increased motion and intradiscal pressures at adjacent levels. Cervical disc arthroplasty (CDA) is an alternative treatment for cervical radiculopathy and myelopathy resulting from degenerative disc disease. By maintaining segmental motion, surgeons hope to avoid some of the primary drawbacks of anterior cervical discectomy and fusion (ACDF), such as pseudoarthrosis and adjacent segment disease. First introduced in the 1960s, CDA has evolved over the years with changes to implant geometry and materials. Early devices produced suboptimal outcomes, but more recent generations of implants have shown long-term outcomes rivaling or even surpassing those of ACDF. In this article, the rationale for CDA as well as the history of such devices is reviewed.
\end{abstract}

Special Issue-Total Disc Replacement

Keywords: cervical, disc arthroplasty, disc replacement, history, rationale

\section{INTRODUCTION}

Anterior cervical discectomy and fusion (ACDF), first described in 1958 by Smith and Robinson, ${ }^{1}$ has been widely adopted as a standard treatment for cervical disc herniations unresponsive to conservative treatment as well as for cervical spondylotic radiculopathy and/or myelopathy. With the exception of the addition of anterior plate fixation and biologic substitutes, the procedure has remained largely unchanged, in part due to its reproducible results and good long-term clinical outcomes. ${ }^{2}$ ACDF is not without drawbacks, however, and efforts to address its limitations have led to the development of cervical disc arthroplasty (CDA). The rationale for motion preservation and the history of CDA will be expanded upon herein.

\section{Rationale for Motion Preservation}

Structural autologous iliac crest bone graft (ICBG) was used in the original description of the ACDF procedure and had traditionally been considered the gold standard. ${ }^{1}$ In a recent survey of over 5000 spine surgeons worldwide, however, only $20 \%$ reported using ICBG autograft in their routine single-level ACDFs. ${ }^{3}$ This is likely due to the drawbacks associated with this graft choice. Besides the additional operative time necessary to harvest structural autologous ICBG, patients may experience complications including persistent pain, neurologic injuries, seromas, hematomas, infection, vascular injuries, and pelvic fractures. ${ }^{4}$ Chronic pain is a commonly reported complication of graft harvest, with as many as $16.5 \%$ of patients reporting more severe pain at the harvest location than at the primary surgical site 1 year after surgery. ${ }^{5}$

It is therefore not surprising that many surgeons have moved away from ICBG. Structural allograft and cages made of polyether ether ketone (PEEK) and/or metals are now more prevalent in ACDF. ${ }^{3}$ However, these graft choices lack the biologic components of autologous ICBG. Pseudoarthrosis, a well-documented complication of ACDF, is commonly defined as failure of solid fusion at 1 year postoperatively and has been linked to poor clinical outcomes. ${ }^{6}$ A meta-analysis of prospective studies on the fusion rates associated with ACDF using anterior plate fixation reported a single-level pseudoarthrosis rate of $3.7 \% .^{7}$ Multiple studies have reported greater nonunion rates in multilevel procedures, and the incidence of pseudoarthrosis tends to increase with the number of levels included in the construct. 8,9

In the early 2000s, surgeons experimented with recombinant human bone morphogenetic protein-2 (rhBMP2) use in the anterior cervical spine in an effort to increase fusion rates. Utilization in the anterior cervical spine declined after multiple studies reported significant and even life-threatening com- 
plications, including postoperative prevertebral swelling, dysphagia, and heterotopic bone formation. ${ }^{10,11}$ Efforts to improve the environment for fusion in PEEK and metal cages have more recently led to investigation into surface technologies, which may improve the fusion rate but also add cost.

Despite the above concerns regarding graft choice and pseudoarthrosis risk, most ACDF procedures produce fairly reliable symptomatic relief and go on to fusion. ${ }^{2,7}$ Patients undergoing single-level arthrodesis experience no decrease in global cervical range of motion (ROM), but fusing greater numbers of levels is associated with progressive loss of global motion $\left(7.1^{\circ}\right.$ with 2 levels, $17.9^{\circ}$ with 3 levels, and $22.1^{\circ}$ with 4 levels). ${ }^{12}$ Furthermore, biomechanical analysis has demonstrated that fusion of even a single cervical motion segment results in motion compensation distributed throughout the remainder of the unfused levels, particularly at the segments immediately cranial and caudal to the surgical level. ${ }^{13}$ Intradiscal pressures in adjacent levels are thereby increased, which is believed to accelerate the degenerative process at these neighboring levels, contributing to increased radiographic adjacent segment degeneration and clinical adjacent segment disease. ${ }^{14}$

The incidence of radiographic adjacent segment degeneration after ACDF has been reported to be as high as $92 \%$ at 5 -year follow-up, ${ }^{15}$ but questions arise as to the impact of fusion itself versus the natural history of the overall disease process. In order to address this issue, Matsumoto et $\mathrm{al}^{16}$ performed a prospective magnetic resonance imaging (MRI) study with 10-year follow-up comparing patients who underwent ACDF to healthy controls. ${ }^{16}$ They determined that while both groups demonstrated progression of disc degeneration over the course of 10 years, the incidence of progression at adjacent segments in ACDF patients was greater than that of control subjects, suggesting that fusion does in fact accelerate adjacent segment degeneration.

Clinical adjacent segment disease has been observed in many studies, most famously by Hilibrand et al, ${ }^{17}$ who followed 374 ACDF patients for up to 21 years. Authors observed that $25.6 \%$ of patients had symptomatic adjacent segment disease at the 10-year timepoint, and this developed at a relatively constant incidence of $2.9 \%$ annually over the course of these first 10 years. ${ }^{17}$ Over two-thirds of patients who developed clinical adjacent segment disease experienced symptoms of sufficient severity that they underwent additional surgery.

Given these limitations of ACDF, CDA has spurred interest as an alternative to fusion. Disc arthroplasty, like its fusion counterpart, allows for removal of the offending pathology with restoration of disc height. However, it features the additional benefit of maintained segmental motion, avoids the morbidity of ICBG harvest, and does not suffer from the issue of pseudoarthrosis.

These potential benefits of CDA are demonstrated in the long-term follow-up literature. Two-level CDA has now demonstrated superiority to 2-level ACDF in multiple Level 1 prospective, randomized controlled studies. ${ }^{18,19}$ Furthermore, a 2016 metaanalysis of 8 available randomized controlled trials reporting at least 4-year data on CDA versus ACDF found evidence to conclude that even single-level CDA produces significantly superior results in terms of overall success, neurologic outcome, neck pain improvement, surgery/implant-related serious adverse events, patient satisfaction, radiographic superior adjacent segment degeneration, and secondary surgeries (at both the index and adjacent levels). ${ }^{20}$

\section{History of CDA}

Although the widespread adoption of CDA may seem to be a relatively recent phenomenon, the designs of current implants are a result of decades of iteration. The first CDA was a stainless steel ball bearing device implanted by Ulf Fernstrom in $1966 .^{21}$ However, this prosthesis ultimately fell out of favor due to high rates of complications, including adjacent-segment hypermobility, device migration, and subsidence.

The next generation of CDA devices did not appear for another 2 decades given the relative success of ACDF compared with the Fernstrom implant. Prompted by the popularity of lumbar arthroplasty in Europe in the 1980s, device developers and surgeons began experimenting with new CDA designs in the late 1980s and 1990s. B.H. Cummins at the Frenchay Hospital in Bristol, UK, introduced a CDA in 1989 that consisted of a stainless-steel ball-and-socket design secured with 2 anchoring screws. Initial clinical results of this metal-on-metal device were unsatisfactory-a report of 18 early patients revealed 4 cases of lost fixation, 1 case of instability, and persistent dys- 


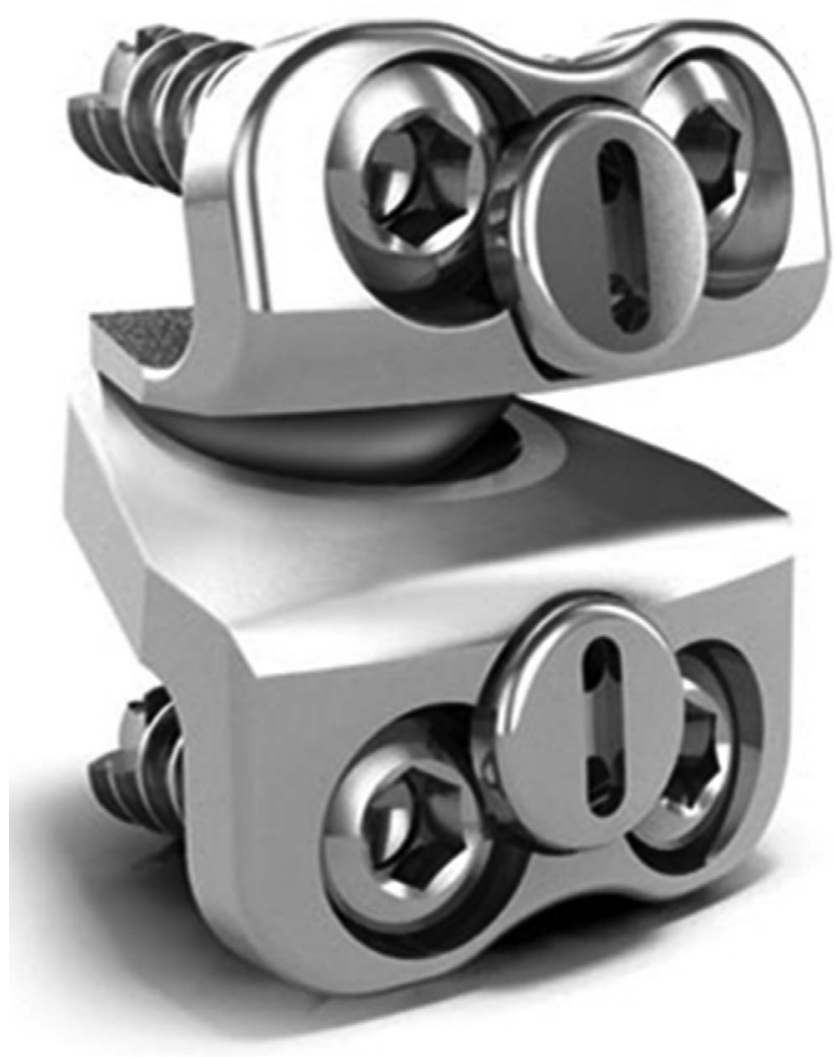

Figure 1. Prestige ST cervical artificial disc. phagia in all 18 patients (possibly as a result of its high-profile design). ${ }^{22}$

The device was subsequently redesigned, with changes made to the device's profile, articulating surface geometry, and anterior locking mechanism. It was reintroduced as the Frenchay cervical disc and produced promising results in a 2002 pilot study. ${ }^{23}$ The device was later purchased by Medtronic, Inc, and renamed the Prestige disc. Results of a randomized clinical trial with 2-year follow-up comparing the outcomes of 276 patients undergoing arthroplasty with the Prestige ST disc (Figure 1) to 265 control patients who underwent ACDF for single level disc degeneration and radiculopathy was published in $2007 .{ }^{24}$ The CDA cohort exhibited a greater rate of neurological success, improved clinical outcomes (Neck Disability Index [NDI], neck pain, return to work), and a lower rate of secondary surgeries (both at the index and adjacent levels) than the ACDF group. There were no cases of implant migration or failure in the CDA group, and the device maintained average segmental sagittal angular motion of greater than $7^{\circ}$ at final follow-up. In light of these data, the Prestige ST received US Food and Drug Administration (FDA) approval in 2007 for the treatment of cervical myelopathy and/or radiculopathy caused by disc herniation from $\mathrm{C} 3$ to $\mathrm{C} 7$ (Table).

Table. Timeline of IDE trial initiation and FDA approval for artificial cervical discs in the United States that have achieved or are currently applying for FDA approval.

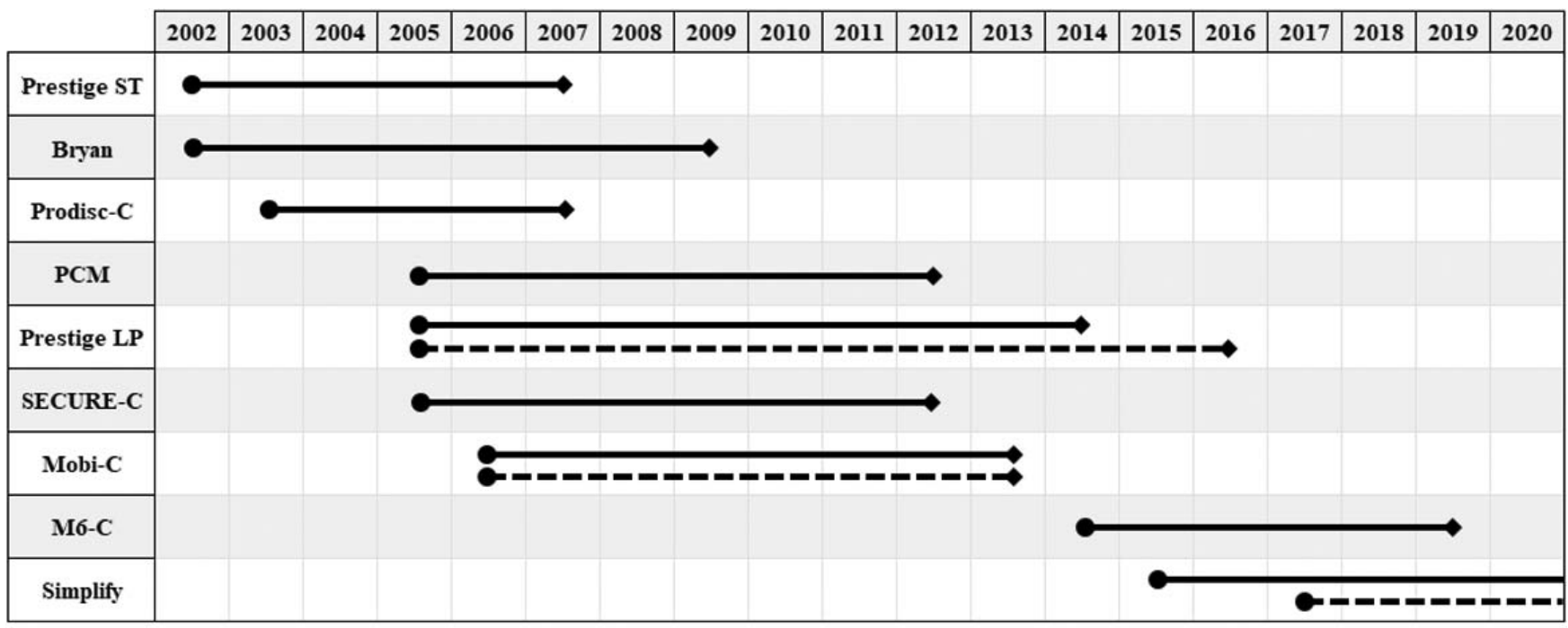

One-level indication

-ーー Two-level indication

IDE trial initiation

FDA approval 


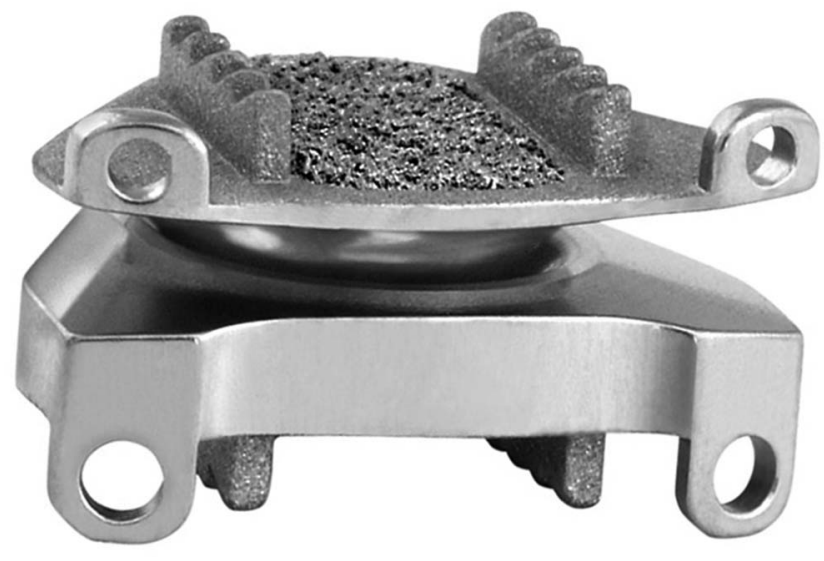

Figure 2. Prestige LP cervical artificial disc.

Although the initial Prestige disc was made of stainless steel, the most recent iteration, the Prestige LP (low profile), is a titanium-ceramic composite that is MRI compatible and features a porous titanium coating to encourage bone in-growth (Figure 2). It received FDA approval as an alternative to ACDF for 1-level pathology from C3 to C7 in 2014 and for 2-level disease in 2016, based on large investigational device exemption (IDE) studies. ${ }^{25,26}$ Ten-year follow-up of the both the single- and 2-level study cohorts are now available - safety and effectiveness were maintained. ${ }^{27,28}$ In the single-level CDA cohort, 10.3\% of patients had undergone a secondary surgery at the index level by 10 years, and $13.8 \%$ had a second surgery an at an adjacent level. In the 2-level study,

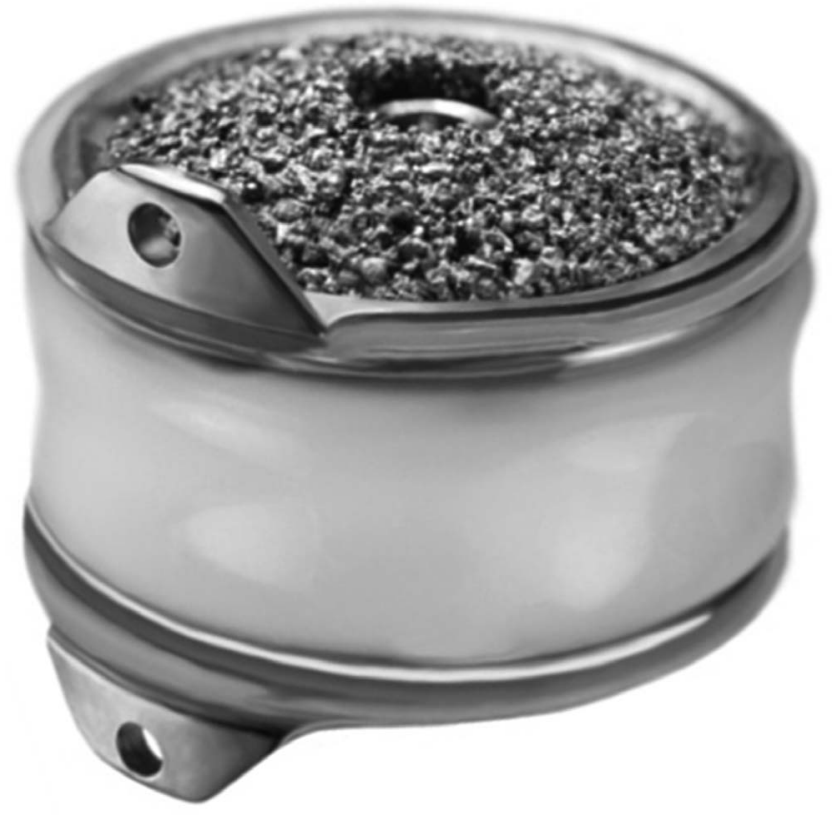

Figure 3. Bryan cervical artificial disc.

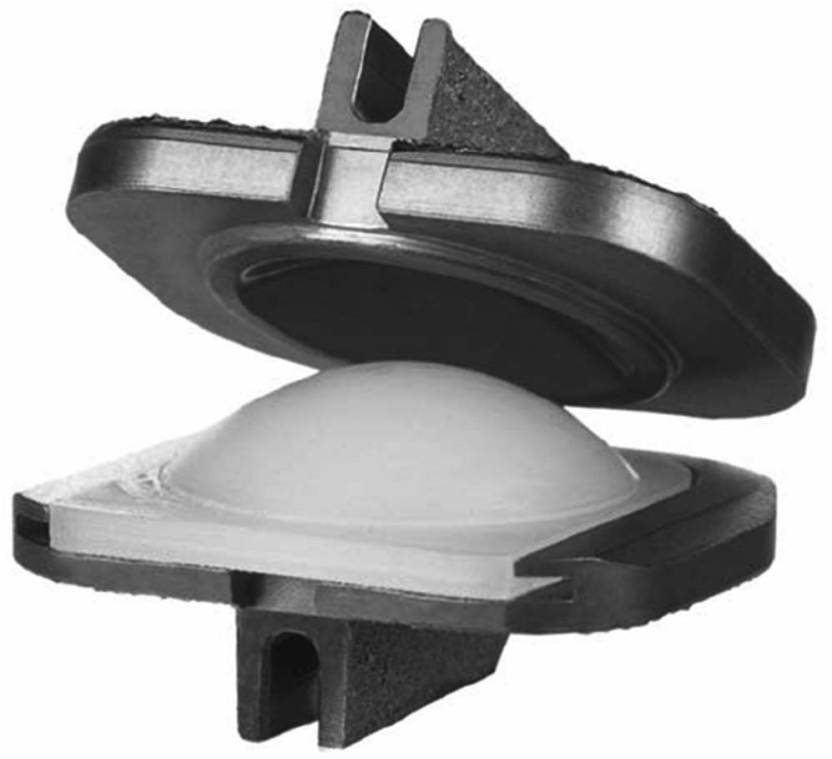

Figure 4. Prodisc-C cervical artificial disc.

the CDA group had significantly higher rates of overall success $(80.4 \%$ versus $62.2 \%)$, NDI success $(88.4 \%$ versus $76.5 \%)$, and neurological success (92.6\% versus $86.1 \%)$. Improvements in NDI and neck pain scores were statistically superior for CDA as well. Patients in the Prestige LP group underwent significantly fewer secondary surgical procedures at the index-level $(4.7 \%$ versus $17.6 \%)$ and at adjacent levels $(9.0 \%$ versus $17.9 \%)$. All other study endpoints were at least noninferior for CDA as

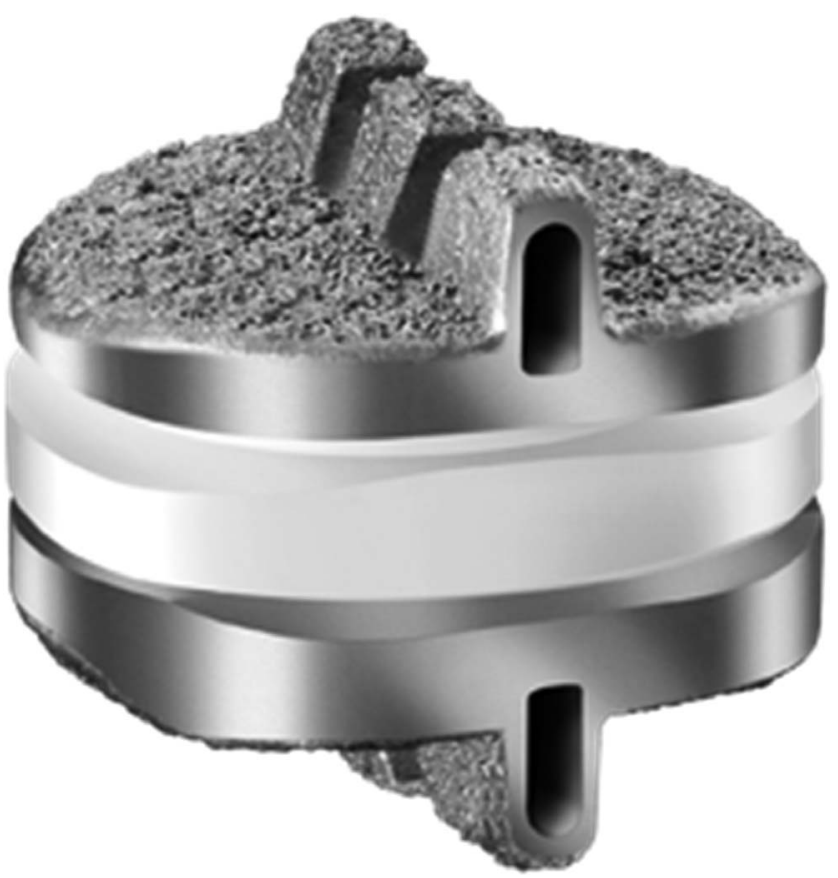

Figure 5. SECURE-C cervical artificial disc. 


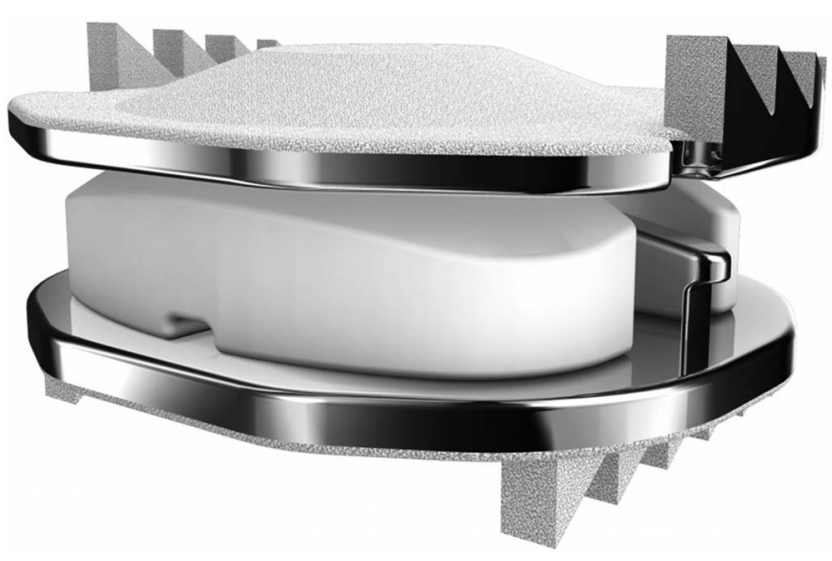

Figure 6. Mobi-C cervical artificial disc.

compared with ACDF. Furthermore, segmental angular ROM was maintained at both treated levels in the CDA group at final follow-up.

Vincent Bryan, an American neurosurgeon, designed the Bryan disc (Medtronic, Inc) in the early 1990s (Figure 3). This metal-on-plastic implant consists of a polyurethane core articulating between 2 titanium endplates with rough surfaces for bone ingrowth. The core is bathed in saline, which is contained by an outer polyurethane membrane to mimic synovial fluid, isolate wear debris, and prevent ingrowth of soft tissue. It is an unconstrained device held in the disc space by "press fit" rather than screw fixation. Ten-year outcomes from the original IDE cohorts have now been published with evidence of maintained motion, a greater rate of overall success composite endpoint $(81.3 \%$ versus

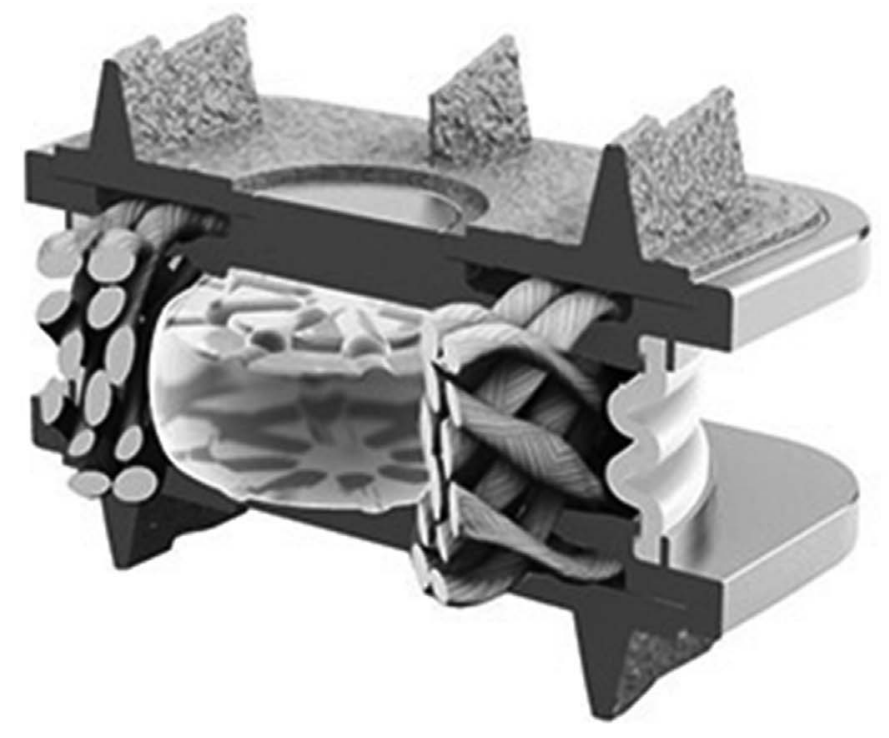

$66.3 \%, P=.005)$, and more improvement in NDI scores in patients (38.3 versus 31.1 decrease, $P=$ .010) with single-level disease receiving the Bryan disc compared with those who underwent ACDF. ${ }^{29}$ A trend toward lower rates of secondary surgeries at the index level were observed with the Bryan disc compared with ACDF, but this did not attain statistical significance $(9.7 \%$ versus $15.8 \%, P=$ .146).

The Prodisc-C (Centinel Spine), developed by surgeons Thierry Marnay and Rudolph Bertagnoli, was first implanted in Europe in 2002 (Figure 4). An FDA IDE study began in the United States the following year. The design of this device paralleled the principles of the ProDisc-L lumbar spine implant - it is a cobalt-chromium on ultra-highmolecular-weight polyethylene ball-and-socket design that features keels on each surface to anchor it to the vertebral endplates above and below. Sevenyear data now available from the original FDA IDE study population demonstrate equivalent clinical outcomes to single-level ACDF with significantly lower probability of secondary surgery $(18 \%$ in the ACDF group, $7 \%$ in the CDA group, $P=.0099) .{ }^{30}$

There has subsequently been a proliferation in CDA devices. Over the years, they have generally become simpler to assemble and insert in order to facilitate surgeon acceptance and standardize outcomes. Currently available FDA-approved implants also include the SECURE-C by Globus Medical, Inc (Figure 5) and the Mobi-C by Zimmer Biomet (Figure 6), which is FDA-approved for 1- and 2-

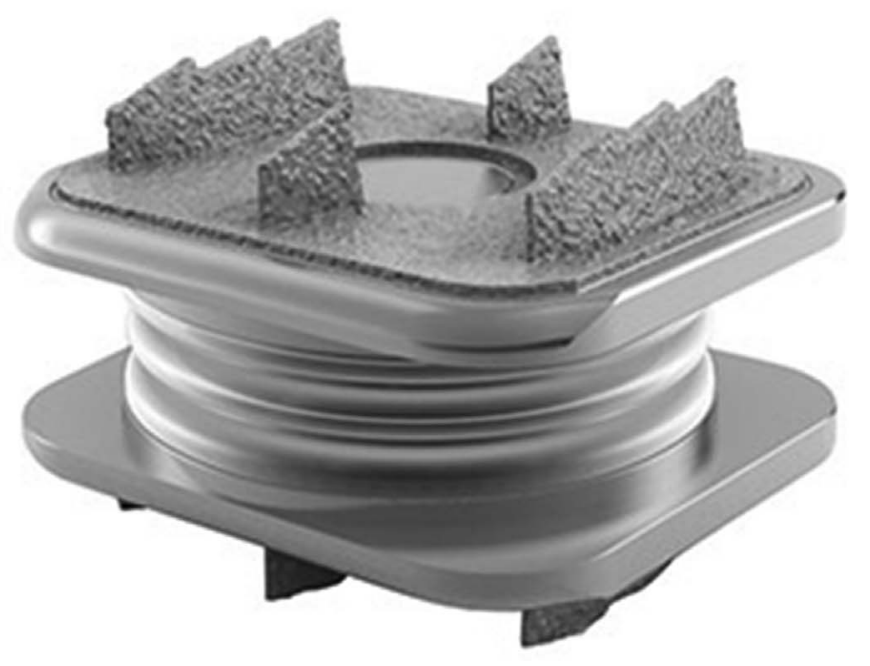

Figure 7. M6-C cervical artificial disc. 


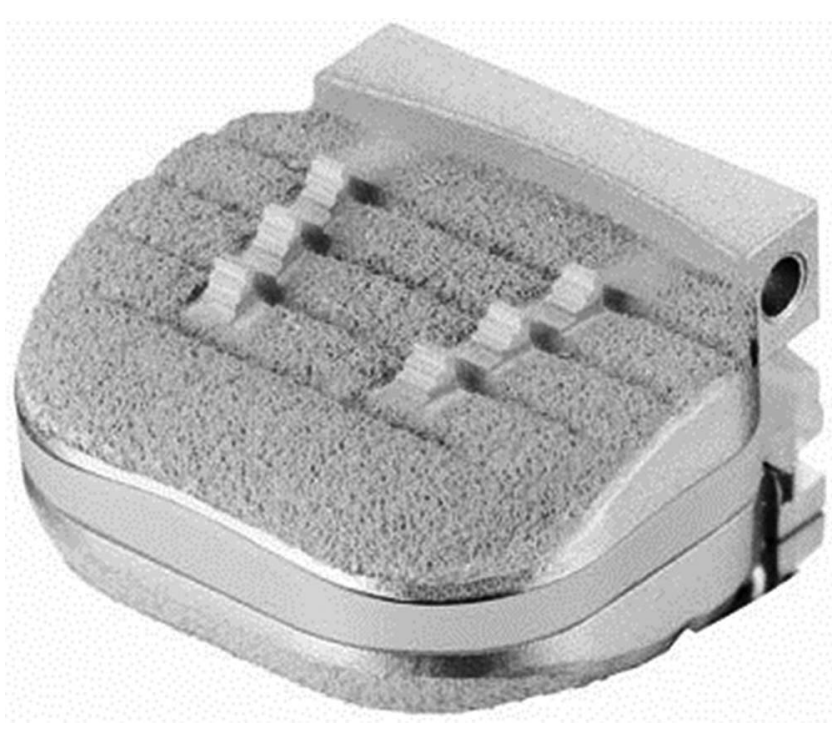

Figure 8. PCM cervical artificial disc.

level use. Seven-year follow-up of the SECURE-C IDE cohorts reveals that this CDA implant produces statistically higher rates of overall success and patient satisfaction $(96.0 \%$ versus $88.8 \%)$ than ACDF. Two-level CDA with the Mobi-C device has shown superiority with respect to 2-level ACDF in a large, multicenter randomized controlled study. ${ }^{19}$ Over the 2-year study window, patients with the Mobi-C experienced greater improvement in NDI scores at all timepoints, maintained their preoperative segmental ROM, and had a lower reoperation rate $(11.4 \%$ versus $3.1 \%)$ than those with ACDF. The M6-C cervical disc (Figure 7), acquired by Orthofix in 2018 and approved for single-level use by the FDA in 2019, is unique in that it features a compressible artificial nucleus (made of polycarbonate urethane) and woven fiber annulus (made of polyethylene) intended to mimic the morphology and biomechanics of a native disc. $^{31,32}$

The PCM disc, at one point offered by NuVasive, Inc, is not currently available on the market, although reasons for this have not been publicized (Figure 8). The Kineflex $\mid \mathrm{C}$, developed by SpinalMotion, Inc, was a metal-on-metal (cobalt chrome molybdenum alloy) implant that completed a successful IDE study $^{33}$ but ultimately did not achieve FDA approval due to concerns regarding metallosis given the bearing surface (Figure 9).

The currently available IDE study results are as follows: For single-level pathology, 2-year outcomes are available for the Prestige ST, ${ }^{24}$ Bryan, ${ }^{34}$ ProdiscC, ${ }^{35} \mathrm{PCM}^{36}$ Prestige LP, ${ }^{25}$ SECURE-C, ${ }^{37}$ Mobi-

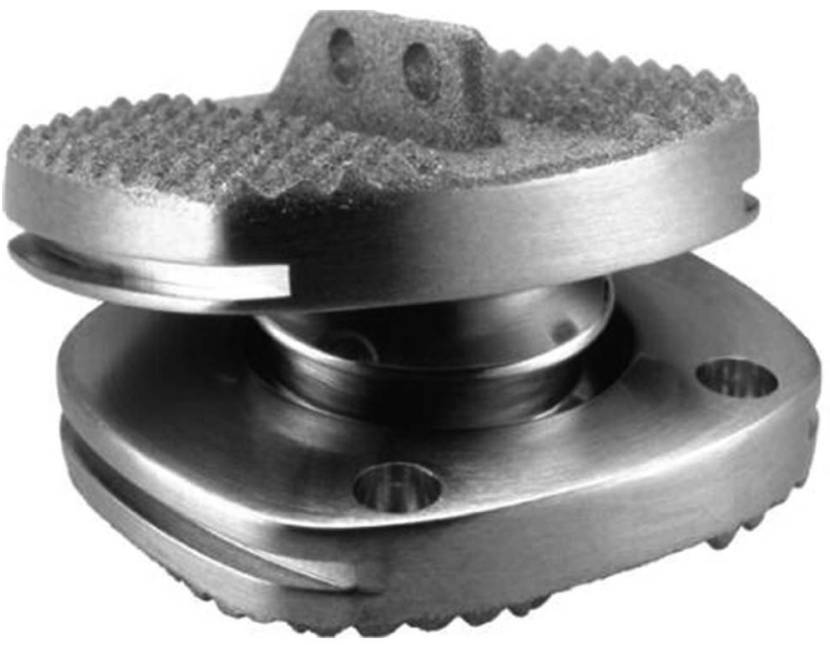

Figure 9. Kineflex $\mid \mathrm{C}$ cervical artificial disc.

$\mathrm{C}^{38}$ and Kineflex $\mid \mathrm{C}^{33}$; 4-year data have been published for the Bryan ${ }^{39}$ and Prodisc- $\mathrm{C}^{40}$; 5-year data are available for the Prestige ST, ${ }^{41}$ Prodisc-C, ${ }^{42}$ $\mathrm{PCM}^{43}$ and Mobi-C ${ }^{44}$; 7-year findings are published for the Prestige ST, ${ }^{45}$ Prodisc-C, ${ }^{30}$ Prestige LP ${ }^{46}$ SECURE-C, ${ }^{47}$ and Mobi-C ${ }^{48}$; and 10-year outcomes are now available for the $\operatorname{Bryan}^{29}$ and Prestige LP $^{27}$ implants. For 2-level surgery, 2-year data are available for the Prestige $\mathrm{LP}^{26}$ and Mobi$\mathrm{C}^{19}$; 4-year ${ }^{49}$ and 5 -year ${ }^{44,50}$ results have been published for Mobi-C; 7-year outcomes are available for the Prestige $\mathrm{LP}^{18}$ and Mobi- $\mathrm{C}^{48}$; and 10year outcomes of the Prestige $\mathrm{LP}^{28}$ have been published.

Additional CDA designs are under development. The Simplify disc (Simplify Medical, Inc) has completed enrollment and is now in the data collection phase of both a 1- and 2-level IDE study (Figure 10). ${ }^{51,52}$ This disc uses PEEK endplates with a ceramic nucleus that produces less MRI artifact

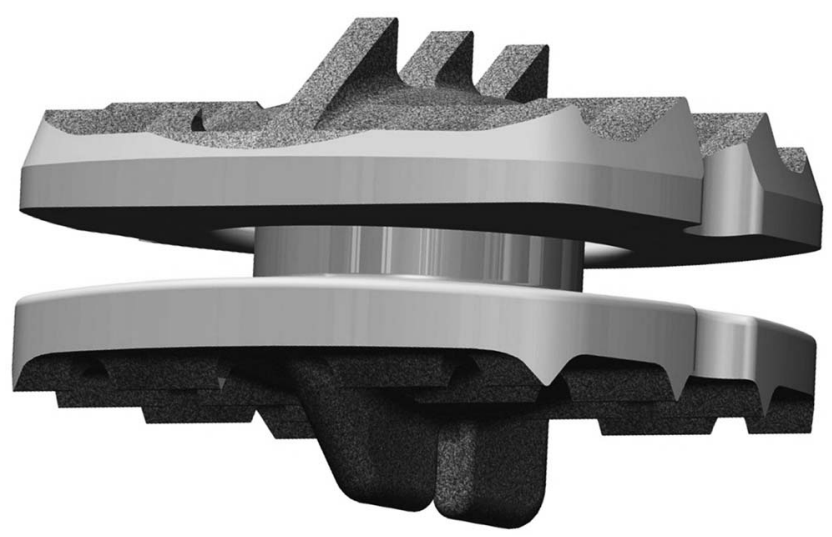

Figure 10. Simplify cervical artificial disc. 

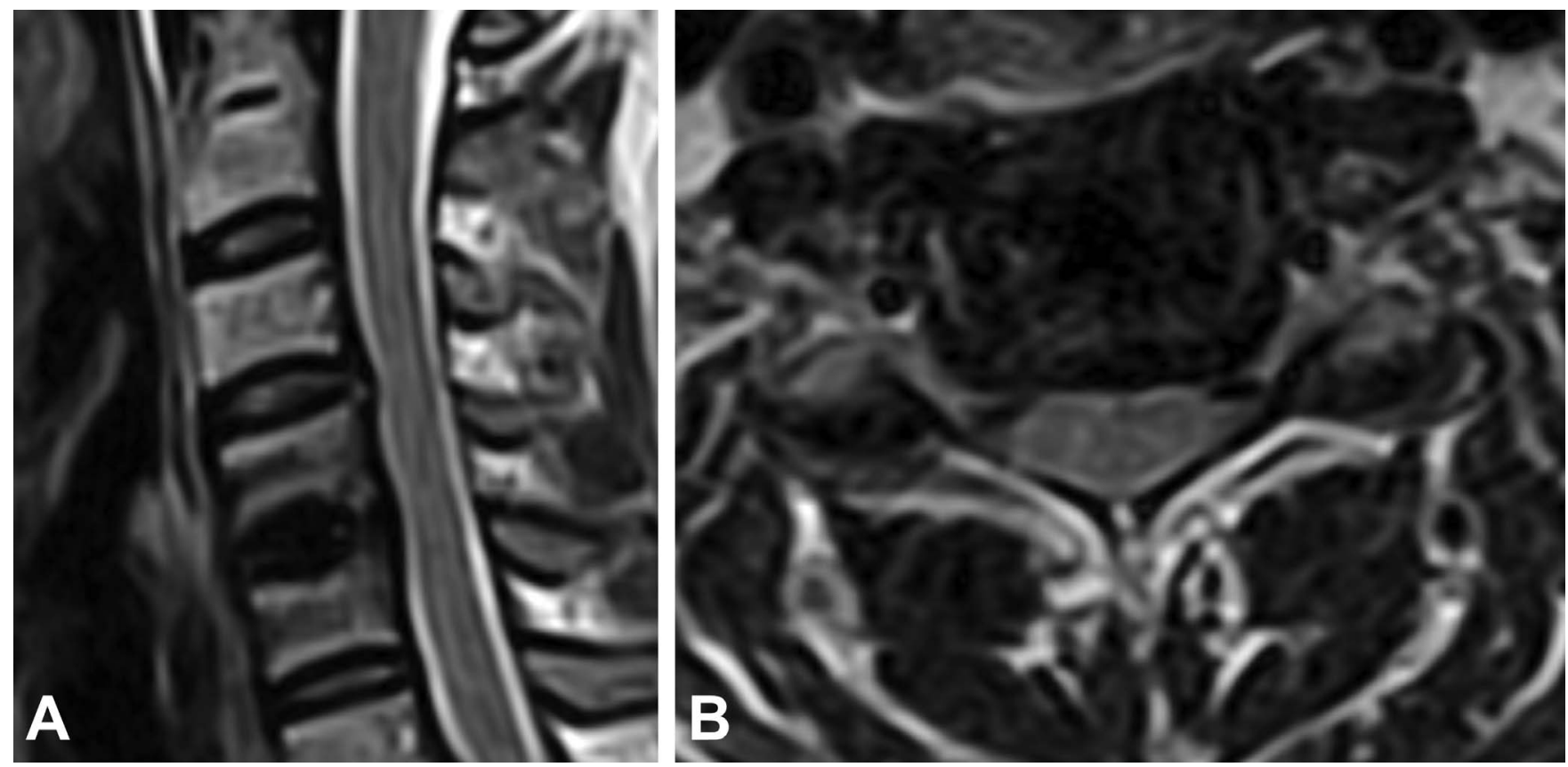

Figure 11. Representative images from a noncontrast MRI performed 2 years status post Simplify cervical disc replacement demonstrating relative lack of artifact: T2 mid-sagittal (A) and T2 axial through the operative level (B).

than the metallic endplates of other designs (Figure 11). There are other implants available outside of the United States that have not undergone the academically rigorous testing necessary for FDA approval.

\section{CONCLUSION}

Cervical disc replacement allows for the treatment of cervical disc disease while maintaining segmental motion. Advantages over traditional ACDF include preservation of ROM, avoidance of pseudoarthrosis, reduction in the incidence of adjacent segment disease, and a dramatic decrease in the need for secondary surgeries at both index and adjacent levels. Although the first CDA was performed over 50 years ago, the technology has gained momentum in the past 2 decades. The growing number of available implants, increasing mainstream adoption, and the availability of highquality data demonstrating superior outcomes to ACDF suggest that CDA could ultimately become the new gold standard treatment for cervical disc disease.

\section{REFERENCES}

1. Smith GW, Robinson RA. The treatment of certain cervical-spine disorders by anterior removal of the intervertebral disc and interbody fusion. J Bone Joint Surg Am. 1958;40A(3):607-624.
2. Buttermann GR. Anterior cervical discectomy and fusion outcomes over 10 years: a prospective study. Spine. 2018;43(3):207-214. doi:10.1097/BRS.0000000000002273

3. Yoon ST, Konopka JA, Wang JC, et al. ACDF graft selection by surgeons: survey of AOSpine members. Glob Spine J. 2017;7(5):410-416. doi:10.1177/2192568217699200

4. Arrington ED, Smith WJ, Chambers HG, Bucknell AL, Davino NA. Complications of iliac crest bone graft harvesting. Clin Orthop. 1996;(329):300-309.

5. Kim DH, Rhim R, Li L, et al. Prospective study of iliac crest bone graft harvest site pain and morbidity. Spine $J$. 2009;9(11):886-892. doi:10.1016/j.spinee.2009.05.006

6. Phillips FM, Carlson G, Emery SE, Bohlman HH Anterior cervical pseudarthrosis. Natural history and treatment. Spine. 1997;22(14):1585-1589.

7. Shriver MF, Lewis DJ, Kshettry VR, Rosenbaum BP, Benzel EC, Mroz TE. Pseudoarthrosis rates in anterior cervical discectomy and fusion: a meta-analysis. Spine $J$. 2015;15(9):2016-2027. doi:10.1016/j.spinee.2015.05.010

8. Brodke DS, Zdeblick TA. Modified Smith-Robinson procedure for anterior cervical discectomy and fusion. Spine. 1992;17(10 suppl):S427-S430.

9. Bohlman HH, Emery SE, Goodfellow DB, Jones PK. Robinson anterior cervical discectomy and arthrodesis for cervical radiculopathy. Long-term follow-up of one hundred and twenty-two patients. $J$ Bone Joint Surg Am. 1993;75(9):1298-1307.

10. Carragee EJ, Hurwitz EL, Weiner BK. A critical review of recombinant human bone morphogenetic protein-2 trials in spinal surgery: emerging safety concerns and lessons learned. Spine J. 2011;11(6):471-491. doi:10.1016/j.spinee.2011.04.023

11. Vaidya R, Carp J, Sethi A, Bartol S, Craig J, Les CM. Complications of anterior cervical discectomy and fusion using recombinant human bone morphogenetic protein-2. Eur Spine J. 2007;16(8):1257-1265. doi:10.1007/s00586-007-0351-9 
12. Lee S-H, Lee JC, Tauchi R, Daniel Riew K. Influence of the number of cervical fusion levels on cervical spine motion and health-related quality of life. Spine. 2016;41(8):E474-E480. doi:10.1097/BRS.0000000000001299

13. Schwab JS, Diangelo DJ, Foley KT. Motion compensation associated with single-level cervical fusion: where does the lost motion go? Spine. 2006;31(21):2439-2448. doi:10.1097/ 01.brs.0000239125.54761.23

14. Eck JC, Humphreys SC, Lim T-H, et al. Biomechanical study on the effect of cervical spine fusion on adjacentlevel intradiscal pressure and segmental motion. Spine. 2002;27(22):2431-2434. doi:10.1097/01.BRS.0000031261.66972.B1

15. Goffin J, Geusens E, Vantomme N, et al. Long-term follow-up after interbody fusion of the cervical spine. $J$ Spinal Disord Tech. 2004;17(2):79-85.

16. Matsumoto M, Okada E, Ichihara D, et al. Anterior cervical decompression and fusion accelerates adjacent segment degeneration: comparison with asymptomatic volunteers in a ten-year magnetic resonance imaging follow-up study. Spine. 2010;35(1):36-43. doi:10.1097/BRS.0b013e3181b8a80d

17. Hilibrand AS, Carlson GD, Palumbo MA, Jones PK, Bohlman HH. Radiculopathy and myelopathy at segments adjacent to the site of a previous anterior cervical arthrodesis. $J$ Bone Joint Surg Am. 1999;81(4):519-528.

18. Lanman TH, Burkus JK, Dryer RG, Gornet MF, McConnell J, Hodges SD. Long-term clinical and radiographic outcomes of the Prestige LP artificial cervical disc replacement at 2 levels: results from a prospective randomized controlled clinical trial. J Neurosurg Spine. 2017;27(1):7-19. doi:10.3171/ 2016.11.SPINE16746

19. Davis RJ, Kim KD, Hisey MS, et al. Cervical total disc replacement with the Mobi-C cervical artificial disc compared with anterior discectomy and fusion for treatment of 2-level symptomatic degenerative disc disease: a prospective, randomized, controlled multicenter clinical trial: clinical article. $J$ Neurosurg Spine. 2013;19(5):532-545. doi:10.3171/2013.6. SPINE12527

20. Hu Y, Lv G, Ren S, Johansen D. Mid- to long-term outcomes of cervical disc arthroplasty versus anterior cervical discectomy and fusion for treatment of symptomatic cervical disc disease: a systematic review and meta-analysis of eight prospective randomized controlled trials. PloS One. 2016;11(2):e0149312. doi:10.1371/journal.pone.0149312

21. Fernström U. Arthroplasty with intercorporal endoprothesis in herniated disc and in painful disc. Acta Chir Scand Suppl. 1966;357:154-159.

22. Cummins BH, Robertson JT, Gill SS. Surgical experience with an implanted artificial cervical joint. J Neurosurg. 1998;88(6):943-948. doi:10.3171/jns.1998.88.6.0943

23. Wigfield CC, Gill SS, Nelson RJ, Metcalf $\mathrm{NH}$, Robertson JT. The new Frenchay artificial cervical joint: results from a two-year pilot study. Spine. 2002;27(22):2446-2452. doi:10.1097/01.BRS.0000032365.21711.5E

24. Mummaneni PV, Burkus JK, Haid RW, Traynelis VC, Zdeblick TA. Clinical and radiographic analysis of cervical disc arthroplasty compared with allograft fusion: a randomized controlled clinical trial. J Neurosurg Spine. 2007;6(3):198-209. doi:10.3171/spi.2007.6.3.198

25. Gornet MF, Burkus JK, Shaffrey ME, Argires PJ, Nian H, Harrell FE. Cervical disc arthroplasty with PRESTIGE LP disc versus anterior cervical discectomy and fusion: a prospective, multicenter investigational device exemption study. J Neurosurg Spine. 2015;23(5):558-573. doi:10.3171/ 2015.1.SPINE14589

26. Gornet MF, Lanman TH, Burkus JK, et al. Cervical disc arthroplasty with the Prestige LP disc versus anterior cervical discectomy and fusion, at 2 levels: results of a prospective, multicenter randomized controlled clinical trial at 24 months. J Neurosurg Spine. 2017;26(6):653-667. doi:10. 3171/2016.10.SPINE16264

27. Gornet M, Burkus JK, Shaffrey ME, Schranck FW, Copay AG. Cervical disc arthroplasty: 10-year outcomes of the Prestige LP cervical disc at a single level. J Neurosurg Spine. 2019;31(3):317-325. doi:10.3171/2019.2.SPINE1956

28. Gornet M, Lanman TH, Burkus JK, et al. Two-level cervical disc arthroplasty versus anterior cervical discectomy and fusion: 10-year outcomes of a prospective, randomized investigational device exemption clinical trial. J Neurosurg Spine. 2019;31:508-518. doi:10.3171/2019.4.SPINE19157

29. Lavelle WF, Riew KD, Levi A, Florman JE. 10-year outcomes of cervical disc replacement with the BRYAN ${ }^{\circledR}$ cervical disc: results from a prospective, randomized, controlled clinical trial. Spine. 2019;44(9):601-608. doi:10.1097/BRS.0000 000000002907

30. Janssen ME, Zigler JE, Spivak JM, Delamarter RB, Darden BV, Kopjar B. ProDisc-C total disc replacement versus anterior cervical discectomy and fusion for single-level symptomatic cervical disc disease: seven-year follow-up of the Prospective Randomized U.S. Food and Drug Administration Investigational Device Exemption Study. J Bone Joint Surg Am. 2015;97(21):1738-1747. doi:10.2106/JBJS.N.01186

31. Lauryssen C, Coric D, Dimmig T, Musante D, Ohnmeiss DD, Stubbs HA. Cervical total disc replacement using a novel compressible prosthesis: results from a prospective Food and Drug Administration-regulated feasibility study with 24-month follow-up. Int J Spine Surg. 2012;6:71-77. doi:10.1016/j.ijsp. 2012.02.001

32. Health C for D and R. M6- $\mathrm{C}^{\mathrm{TM}}$ Artificial Cervical Disc P170036. FDA. December 2019. http://www.fda.gov/medicaldevices/recently-approved-devices/m6-ctm-artificial-cervicaldisc-p170036. Accessed February 23, 2020.

33. Coric D, Nunley PD, Guyer RD, et al. Prospective, randomized, multicenter study of cervical arthroplasty: 269 patients from the Kineflex $\mid \mathrm{C}$ artificial disc investigational device exemption study with a minimum 2-year follow-up: clinical article. J Neurosurg Spine. 2011;15(4):348-358. doi:10.3171/ 2011.5.SPINE10769

34. Heller JG, Sasso RC, Papadopoulos SM, et al. Comparison of BRYAN cervical disc arthroplasty with anterior cervical decompression and fusion: clinical and radiographic results of a randomized, controlled, clinical trial. Spine. 2009;34(2):101-107. doi:10.1097/BRS.0b013e31818ee263

35. Murrey D, Janssen M, Delamarter R, et al. Results of the prospective, randomized, controlled multicenter Food and Drug Administration investigational device exemption study of the ProDisc-C total disc replacement versus anterior discectomy and fusion for the treatment of 1-level symptomatic cervical disc disease. Spine J. 2009;9(4):275-286. doi:10.1016/j.spinee. 2008.05.006

36. Phillips FM, Lee JYB, Geisler FH, et al. A prospective, randomized, controlled clinical investigation comparing PCM cervical disc arthroplasty with anterior cervical discectomy and 
fusion. 2-year results from the US FDA IDE clinical trial. Spine. 2013;38(15):E907-E918. doi:10.1097/BRS.0b013e31829 $6232 \mathrm{f}$

37. Vaccaro A, Beutler W, Peppelman W, et al. Clinical outcomes with selectively constrained SECURE-C cervical disc arthroplasty: two-year results from a prospective, randomized, controlled, multicenter investigational device exemption study. Spine. 2013;38(26):2227-2239. doi:10.1097/BRS.000000000000 0031

38. Hisey MS, Bae HW, Davis R, et al. Multi-center, prospective, randomized, controlled investigational device exemption clinical trial comparing Mobi-C Cervical Artificial Disc to anterior discectomy and fusion in the treatment of symptomatic degenerative disc disease in the cervical spine. Int J Spine Surg. 2014;8. doi:10.14444/1007

39. Sasso RC, Anderson PA, Riew KD, Heller JG. Results of cervical arthroplasty compared with anterior discectomy and fusion: four-year clinical outcomes in a prospective, randomized controlled trial. J Bone Joint Surg Am. 2011;93(18):16841692. doi:10.2106/JBJS.J.00476

40. Delamarter RB, Murrey D, Janssen ME, et al. Results at 24 months from the prospective, randomized, multicenter Investigational Device Exemption trial of ProDisc-C versus anterior cervical discectomy and fusion with 4-year follow-up and continued access patients. SAS J. 2010;4(4):122-128. doi:10.1016/j.esas.2010.09.001

41. Burkus JK, Haid RW, Traynelis VC, Mummaneni PV. Long-term clinical and radiographic outcomes of cervical disc replacement with the Prestige disc: results from a prospective randomized controlled clinical trial. J Neurosurg Spine. 2010;13(3):308-318. doi:10.3171/2010.3.SPINE09513

42. Zigler JE, Delamarter R, Murrey D, Spivak J, Janssen M. ProDisc-C and anterior cervical discectomy and fusion as surgical treatment for single-level cervical symptomatic degenerative disc disease: five-year results of a Food and Drug Administration study. Spine. 2013;38(3):203-209. doi:10.1097/ BRS.0b013e318278eb38

43. Phillips FM, Geisler FH, Gilder KM, Reah C, Howell KM, McAfee PC. Long-term outcomes of the US FDA IDE prospective, randomized controlled clinical trial comparing PCM cervical disc arthroplasty with anterior cervical discectomy and fusion. Spine. 2015;40(10):674-683. doi:10.1097/BRS. 0000000000000869

44. Jackson RJ, Davis RJ, Hoffman GA, et al. Subsequent surgery rates after cervical total disc replacement using a MobiC Cervical Disc Prosthesis versus anterior cervical discectomy and fusion: a prospective randomized clinical trial with 5-year follow-up. J Neurosurg Spine. 2016;24(5):734-745. doi:10.3171/ 2015.8.SPINE15219

45. Burkus JK, Traynelis VC, Haid RW, Mummaneni PV. Clinical and radiographic analysis of an artificial cervical disc: 7-year follow-up from the Prestige prospective randomized controlled clinical trial: Clinical article. J Neurosurg Spine. 2014;21(4):516-528. doi:10.3171/2014.6.SPINE13996

46. Gornet MF, Burkus JK, Shaffrey ME, Nian H, Harrell FE. Cervical disc arthroplasty with Prestige LP disc versus anterior cervical discectomy and fusion: seven-year outcomes. Int J Spine Surg. 2016;10:24. doi:10.14444/3024
47. Vaccaro A, Beutler W, Peppelman W, et al. Long-term clinical experience with selectively constrained SECURE-C cervical artificial disc for 1-level cervical disc disease: results from seven-year follow-up of a prospective, randomized, controlled investigational device exemption clinical trial. Int $J$ Spine Surg. 2018;12(3):377-387. doi:10.14444/5044

48. Radcliff K, Davis RJ, Hisey MS, et al. Long-term evaluation of cervical disc arthroplasty with the Mobi-C(C) cervical disc: a randomized, prospective, multicenter clinical trial with seven-year follow-up. Int J Spine Surg. 2017;11:31. doi: $10.14444 / 4031$

49. Davis RJ, Nunley PD, Kim KD, et al. Two-level total disc replacement with Mobi-C cervical artificial disc versus anterior discectomy and fusion: a prospective, randomized, controlled multicenter clinical trial with 4-year follow-up results. J Neurosurg Spine. 2015;22(1):15-25. doi:10.3171/ 2014.7.SPINE13953

50. Radcliff K, Coric D, Albert T. Five-year clinical results of cervical total disc replacement compared with anterior discectomy and fusion for treatment of 2-level symptomatic degenerative disc disease: a prospective, randomized, controlled, multicenter investigational device exemption clinical trial. J Neurosurg Spine. 2016;25(2):213-224. doi:10.3171/2015. 12.SPINE15824

51. Investigation of the Simplify ${ }^{\circledR}$ Cervical Artificial Disc Full Text View - ClinicalTrials.gov. https://clinicaltrials.gov/ ct2/show/NCT02667067. Accessed February 23, 2020.

52. Investigation of the Two Level Simplify ${ }^{\circledR}$ Cervical Artificial Disc - Full Text View - ClinicalTrials.gov. https:// clinicaltrials.gov/ct2/show/NCT03123549. Accessed February 23, 2020 .

Disclosures and COI: Dr. Derman declares the following relationships: Consultant agreements with Degen Medical, Orthofix, and Neo Spine. Teaching for Joimax. Research support from Aesculap and Orthofix. Dr. Zigler declares the following relationships: Consultant agreements with Aesculap, Centinel Spine, Medtronic, Orthofix, Simplify Medical. No outside sources of funding were utilized for the preparation of this manuscript.

Corresponding Author: Peter B. Derman, MD, MBA, Texas Back Institute, $6020 \mathrm{~W}$. Parker Road, Suite 200, Plano, TX 75093. Phone: (972) 608-5000; Fax: (972) 608-5068; Email: pderman@ texasback.com.

Published 30 September 2020

This manuscript is generously published free of charge by ISASS, the International Society for the Advancement of Spine Surgery. Copyright (c) 2020 ISASS. To see more or order reprints or permissions, see http://ijssurgery.com. 